\title{
Current practice of cervical disc arthroplasty: a survey among 383 AOSpine International members
}

\author{
*Timothy C. Chin-See-Chong, BSc, ${ }^{1}$ Pravesh S. Gadjradj, BSc, ${ }^{1}$ Robert J. Boelen, MD, ${ }^{2}$ and \\ Biswadjiet S. Harhangi, MD, PhD, MSc ${ }^{1}$
}

1Department of Neurosurgery, Erasmus MC University Medical Center Rotterdam, and ${ }^{2}$ Kliniek Lange VoorhouT, Rijswijk, The Netherlands

OBJECTIVE The use of cervical disc arthroplasty (CDA) in spinal practice is controversial. This may be explained by the lack of studies with a large sample size and long-term outcomes. With this survey the authors aimed to evaluate the opinions of spine surgeons on the use of CDA in the current treatment of cervical disc herniation (CDH).

METHODS A web-based survey was sent to all members of AOSpine International by email using SurveyMonkey on July 18, 2016. A single reminder was sent on August 18, 2016. Questions included geographic location; specialty; associated practice model; number of discectomies performed annually; the use of CDA, anterior cervical discectomy (ACD), and anterior cervical discectomy and fusion (ACDF); and the expectations for clinical outcomes of these procedures.

RESULTS A total of 383 questionnaires were analyzed. Almost all practitioners (97.9\%) were male, with a mean of 15.0 \pm 9.7 years of clinical experience. The majority of responders were orthopedic surgeons (54.6\%). $84.3 \%$ performed ACDF as the standard technique for $\mathrm{CDH} .47 .8 \%$ of the surgeons occasionally used CDA, whereas $7.3 \%$ used CDA as standard approach for $\mathrm{CDH}$. The most common arthroplasty device used was the ProDisc-C. Low evidence for benefits and higher costs were the most important reasons for not offering CDA. The risk of adjacent-level disease was considered smaller for CDA as compared with ACDF. However, ACDF was expected to have the highest effectiveness on arm pain (87.5\%), followed by CDA (77.9\%), while ACD had the least (12.6\%).

CONCLUSIONS In this survey, CDA was not considered to be the routine procedure to treat CDH. Reported benefits included the reduced risk of adjacent-level disease and preservation of motion of the neck. Lack of enough evidence on its effectiveness as well as higher costs were considered to be disadvantages of CDA. More research should be conducted on the implementation impact of CDA and the cost-effectiveness from society's perspective.

https://thejns.org/doi/abs/10.3171/2016.11.FOCUS16338

KEY WORDS cervical disc arthroplasty; cervical disc herniation; total disc replacement

$\mathrm{C}$ ERVICAL disc herniation $(\mathrm{CDH})$ is a common cause of cervical radiculopathy. In a population-based study conducted in the US between 1976 and 1990, the annual age-adjusted incidence for $\mathrm{CDH}$ was 83.2 per $100,000 .{ }^{24}$ A similar study was performed for 2000-2009, and showed an incidence of 1.79 per 1000 person-years. ${ }^{30}$ Symptomatic $\mathrm{CDH}$ can be very debilitating and has an important impact on the patient's overall health status, causing loss of production. ${ }^{4,39}$ Surgical treatment of CDH is usually offered when conservative treatment fails after a minimum of 6 weeks of radiculopathy. ${ }^{3}$

Anterior cervical discectomy (ACD) is the basic surgical treatment for patients with radicular pain caused by CDH. In 1958, Smith and Robinson first described anterior cervical decompression with the use of autologous iliac crest interbody graft (now known as anterior cervical discectomy and fusion $[\mathrm{ACDF}])^{32}$ They described ACDF as a treatment for degenerative spondylotic conditions. Beside eliminating painful motion and allowing decompression of the neural elements with enough stabilization of the affected spine segments, fusion was also offered as an opportunity to remove pathological processes such as infections, arthritis, or deformity.

For CDH, ACDF is accepted as standard surgical treatment for cervical radiculopathy with or without myelopathy. ${ }^{5,18}$ Although there is no clear evidence of the clinical benefits of fusion over no fusion, it has been reported that ACDF may cause adjacent-level disease (ALD) ${ }^{10}$ often requiring reoperation or conservative treatment. ${ }^{36,37}$ Symptoms are similar to those of pseudarthrosis, with neck pain, radiating arm and shoulder pain, and stiffness of the neck. Abnormal loading stress on the adjacent levels

ABBREVIATIONS ACD = anterior cervical discectomy; ACDF = anterior cervical discectomy and fusion; $A L D=$ adjacent-level disease; CDA = cervical disc arthroplasty; $\mathrm{CDH}=$ cervical disc herniation; $\mathrm{RCT}=$ randomized controlled trial.

SUBMITTED September 30, 2016. ACCEPTED November 15, 2016.

INCLUDE WHEN CITING DOI: 10.3171/2016.11.FOCUS16338.

* Mr. Chin-See-Chong and Mr. Gadjradj contributed equally to this work. 


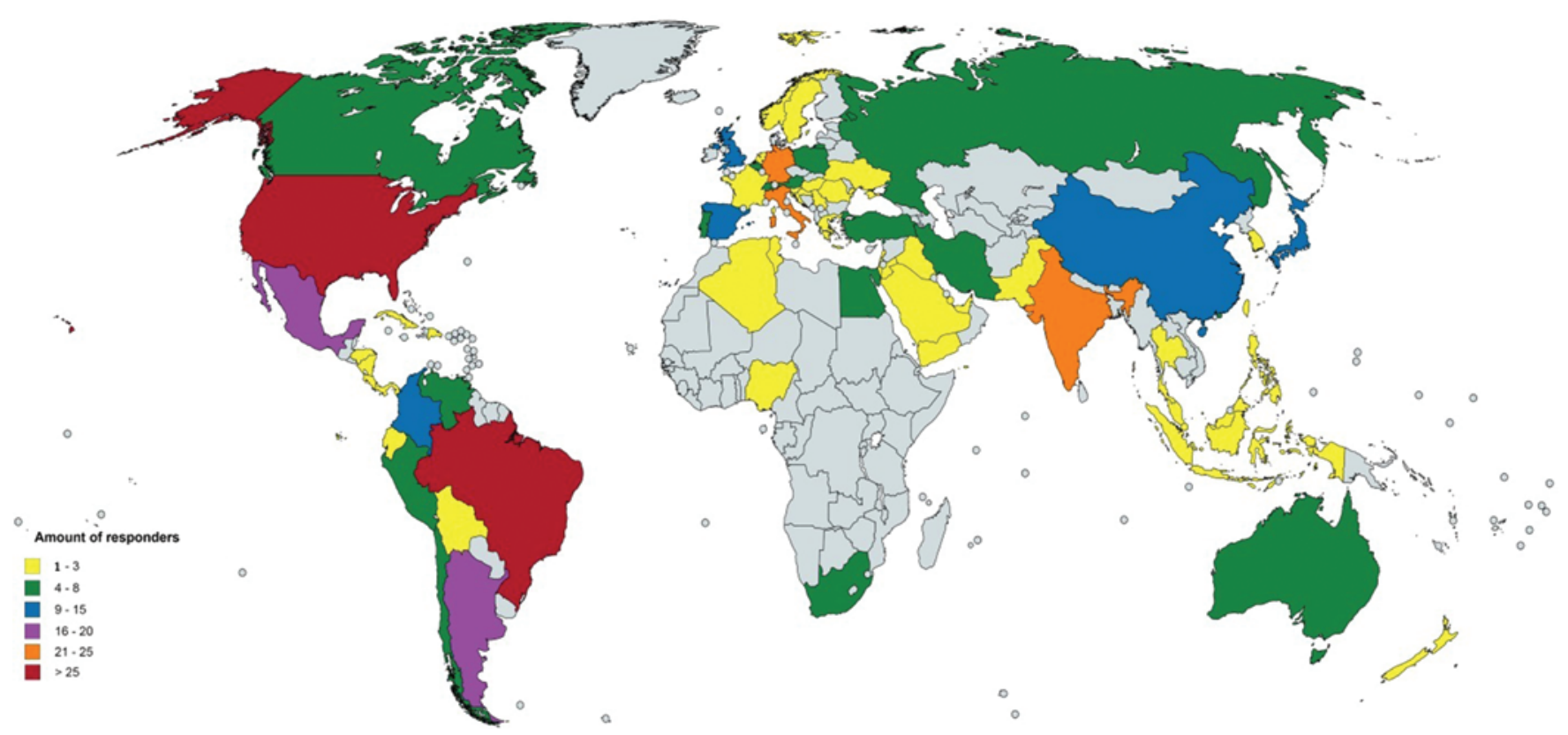

FIG. 1. Map showing geographic distribution of the respondents $(\mathrm{N}=383)$.

due to fusion is hypothesized to cause ALD. ${ }^{14,31,35}$ Another theory is that damage to the anterior longitudinal ligament or longus colli muscles during ACDF may cause ALD. ${ }^{9}$

Artificial disc replacement, also known as total disc arthroplasty or cervical disc arthroplasty (CDA), is a less frequently performed technique to treat symptomatic $\mathrm{CDH}$. During this procedure an artificial device is inserted between 2 vertebrae in the neck to replace the disc in the cervical spine. Several studies have already suggested that CDA may prevent ALD by preserving movement, ${ }^{6,38}$ and may even have a lower reoperation rate. ${ }^{37}$

In 1966, Ulf Fernström was the first to describe the use of a device during a cervical discectomy. He inserted an intracorporal endoprosthesis shaped like a metal bearing into the disc space. ${ }^{8,13}$ Nowadays, there are many types of CDA devices approved by the US FDA: Mobi-C, the Prestige, the ProDisc-C, the Bryan Cervical Disc, the SECURE-C, and the PCM device. ${ }^{2}$ The Mobi-C is the only device approved for both 1- and 2-level use. ${ }^{1}$

Throughout the years, many studies comparing CDA and ACDF have been published, but most have had a short duration of follow-up. ${ }^{15,17,25,26,34,42}$ A recent meta-analysis of 8 randomized controlled trials (RCTs) with at least 48 months of follow-up showed that CDA was superior to ACDF based on arm pain, neck pain, functional improvement, neurological success, and rates of serious adverse events. ${ }^{11}$ Although these studies suggested that CDA has advantages over ACDF, a clear consensus on this subject is still lacking. This may be one of the reasons for surgeons not to adopt CDA as a standard treatment for $\mathrm{CDH} .{ }^{37}$ This study aims to address the current use of CDA for $\mathrm{CDH}$ among an international group of spine surgeons.

\section{Methods}

A web-based survey (questionnaire) was sent to all members of AOSpine International by email using Sur-
veyMonkey, Inc., on July 18, 2016. AOSpine is an international community of spine surgeons, orthopedic surgeons, neurosurgeons, academics, researchers, and other spine care professionals. At the time of this survey there were 6179 members. To improve the response rate, a single reminder was sent on August 18, 2016. The questionnaire consisted of 17 questions, starting with demographic and geographic information of the respondents. This was followed by different aspects of treatment: clinical aspects as indication for surgical treatment, standard technique used, and whether CDA is performed. If not, respondents were asked to rank the following reasons for not offering CDA: cost, complications, legal concerns, insurance issues, low concern for pseudarthrosis, and low evidence for benefit. Furthermore, respondents were asked for their expectations of treatment outcome and disadvantages of CDA, ACD, and ACDF. Last, opinions on the effect of patient or lifestyle factors on clinical outcomes were asked, including smoking, age, the ratio of preoperative neckpain and arm pain, body mass index, prescribing a cervical collar, and diabetes. No approval from the institutional review board was required, because no patients were involved.

Responses from residents and members not performing cervical disc surgery were excluded. Each question was analyzed separately and missing data were excluded from the analyses. All statistical analyses were performed using the Statistical Package for Social Sciences, version 21.0 for Windows (SPSS, Inc.). Mainly descriptive statistics were used to describe our results. A p value of $<0.05$ was considered to be statistically significant.

\section{Results}

A total of 387 members, representing 67 countries, responded (response rate 6.3\%) (Fig. 1). Four respondents (2 residents, 1 surgeon not performing cervical discectomies, and 1 who answered with a blank questionnaire) were ex- 
TABLE 1. Demographic data of 383 respondents to a questionnaire on CDA

\begin{tabular}{lc}
\hline \multicolumn{1}{c}{ Demographic Data } & $\%^{*}$ \\
\hline Sex & 97.9 \\
\hline Male & $15.0 \pm 9.7$ \\
\hline Years of clinical practice (mean \pm SD) & \\
\hline Function & 43.3 \\
\hline Neurosurgeon & 54.6 \\
\hline Orthopedic surgeon & 2.1 \\
\hline Other & 31.8 \\
\hline Employment site & 36.2 \\
\hline Private practice & 32.0 \\
\hline Nonacademic hospital & \\
\hline Academic hospital & 20.1 \\
\hline No. of cervical disc surgeries performed annually & 29.8 \\
\hline $1-10$ & 34.6 \\
\hline $11-25$ & 4.2 \\
\hline $26-50$ & 11.3 \\
\hline $51-75$
\end{tabular}

* Except for years of clinical practice, all values are given as percentages.

cluded, leaving 383 respondents for analysis. Of these, $97.9 \%$ were male, and the surgeons had a mean of 15.0 \pm 9.7 years of clinical experience (Table 1). No difference in experience was observed between orthopedic and neurosurgeons $(\mathrm{p}=0.620, \mathrm{t}$-test). Annually, the respondents perform an average of $34.7 \pm 27.0$ procedures for $\mathrm{CDH}$. Cervical discectomy was more frequently performed by neurosurgeons than by orthopedic surgeons $(41.5 \pm 2.2$ vs $29.5 \pm 1.8$, respectively; $\mathrm{p}=0.038$, t-test).

Pain medication and exercise therapy were expected to have the highest effectiveness on cervical radiculopathy, by $73 \%$ and $58 \%$ of the respondents, respectively (Fig. 2). Holistic therapy and a collar were expected to give the lowest effectiveness, by $53.8 \%$ and $54.8 \%$ of the respondents, respectively. When offering surgery, the most important indications were failure of conservative treatment (95.2\%) and the severity of pain and disability (94.8\%) (Fig. 3). The extent of the disc herniation as seen on MRI was considered to be the least important indication (12.2\%). The majority of the surgeons (44.5\%) regarded 4-8 weeks of radiculopathy as the optimal timing to perform surgery, whereas $19.7 \%$ operate earlier than 4 weeks and $35.8 \%$ operate later than 8 weeks.

An ACDF was the standard procedure for the majority $(84.3 \%)$ of the surgeons (Table 2). $47.8 \%$ of the surgeons occasionally performed CDA, whereas $7.3 \%$ performed CDA as the standard approach for $\mathrm{CDH}$. Other techniques (4.2\%) performed as a standard procedure included posterior cervical discectomy, laminoplasty, and nucleoplasty. Among the CDA devices used, ProDisc-C was the most common (33.3\%), followed by the Prestige (disc) LP (10.9\%). Other (21.9\%) less frequently applied devices included the ProDisc-C vivo, Active C, Dymicron, and Rotation.

Reasons for not offering CDA are shown in Fig. 4. Low evidence for benefits of CDA over other surgical techniques and costs were the most important reasons for not offering CDA, by $33.2 \%$ and $29.6 \%$, respectively. Legal concerns and insurance coverage were seen as the least important reasons. Table 3 shows that, compared with

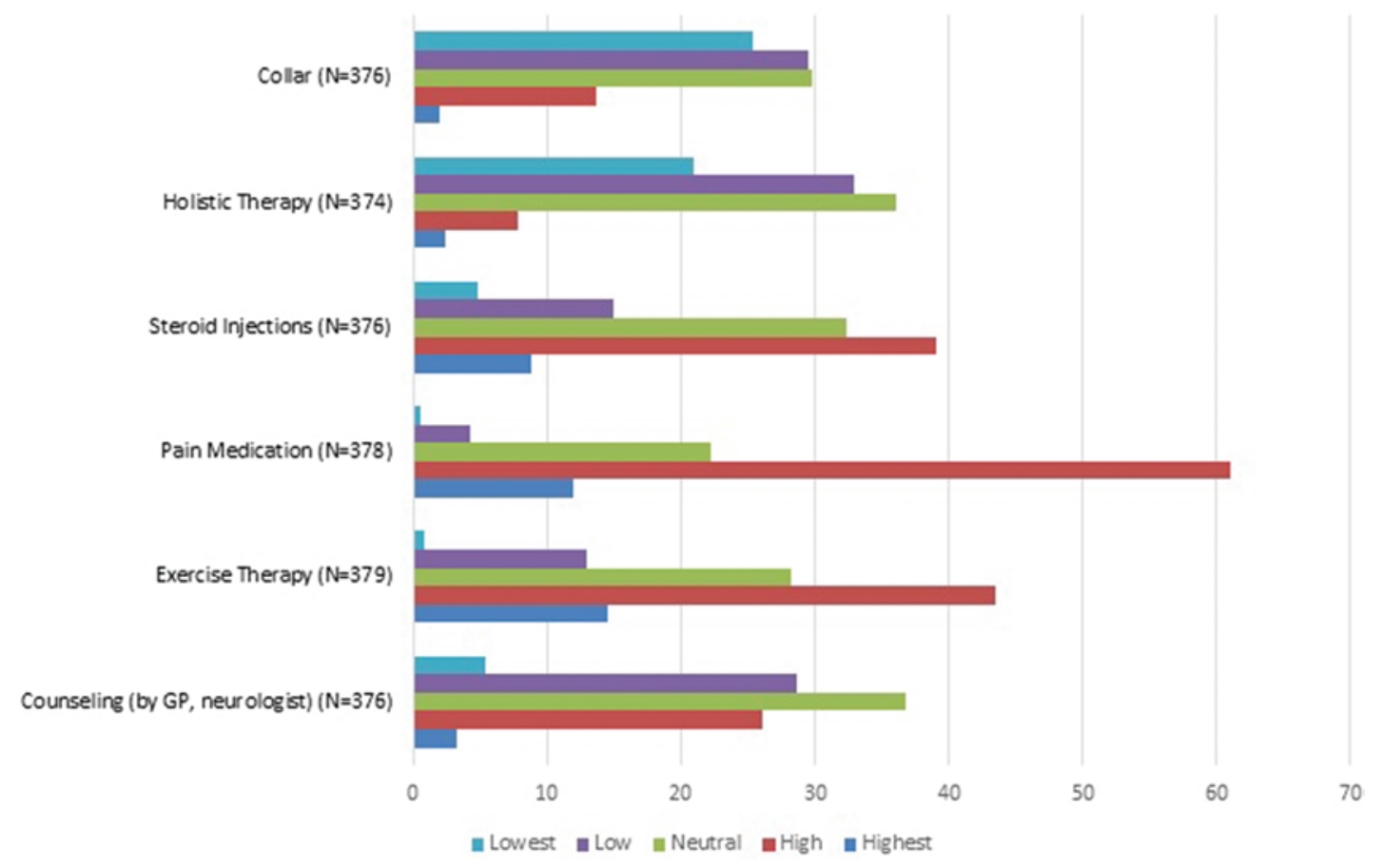

FIG. 2. Graph showing expected effectiveness of conservative treatment modalities (numbers on the x-axis represent percents). $\mathrm{GP}=$ general practitioner. 


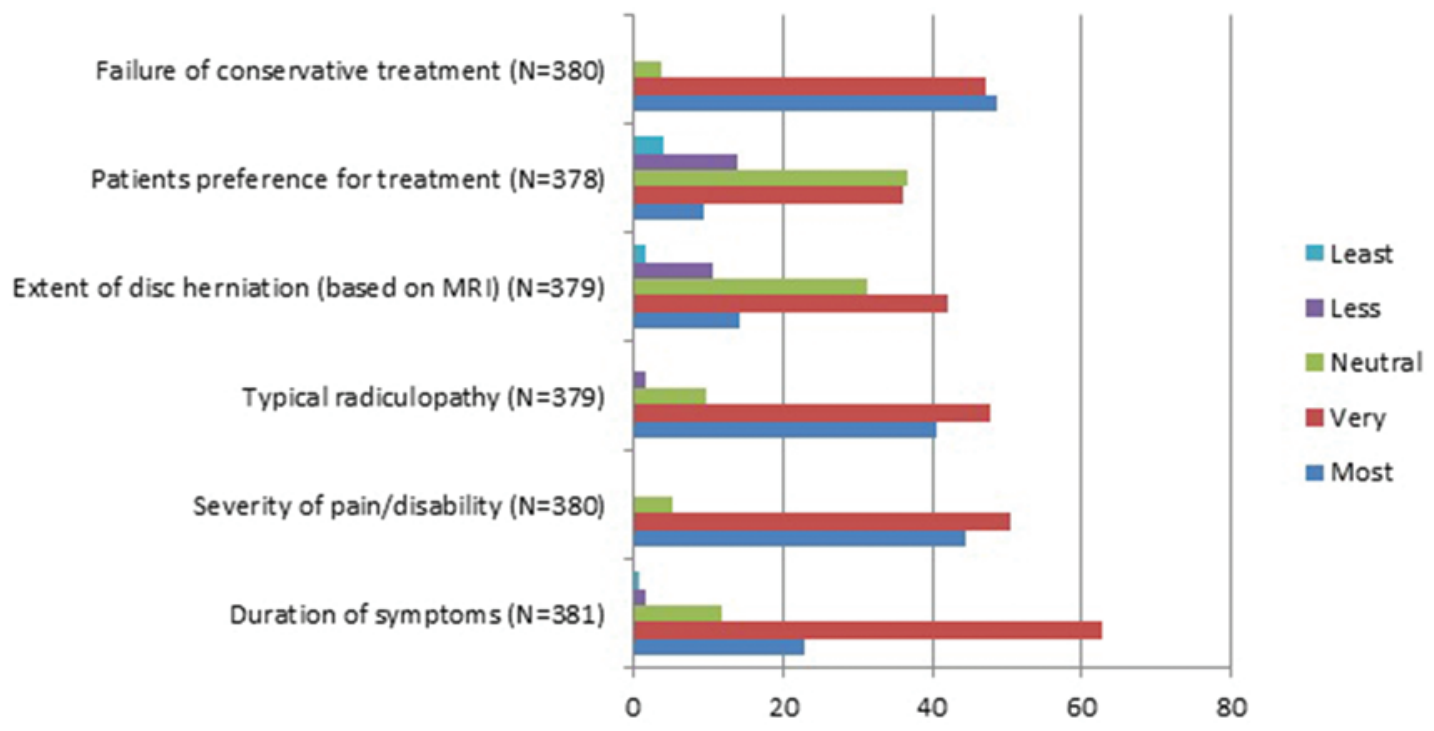

FIG. 3. Graph showing indications for CDH surgery (numbers on the x-axis represent percents).

ACD and ACDF, costs were considered to be the most important disadvantage of CDA (81.4\%), followed by the risk of revision surgery (36.8\%). The CDA procedure was expected to have a lower risk of ALD (54.4\%), whereas ACDF was expected to have the highest risk (47.2\%). Risk of spondylolisthesis was expected to be the smallest for ACDF by $77.3 \%$ of the respondents (Table 3). Most surgeons were neutral on the risk of dysphagia for ACD, $\mathrm{ACDF}$, or CDA.

When comparing CDA with ACDF, preservation of motion of the neck was considered to be the biggest advantage of CDA (44.6\%). Lower risk of ALD and a faster resumption of work and daily activities were other highly ranked advantages of CDA (Fig. 5). When comparing $\mathrm{ACD}, \mathrm{ACDF}$, and CDA, $74.6 \%$ of the surgeons expected CDA to give the fastest rate of return to work and daily ac-

TABLE 2. Standard surgical technique performed by respondents

\begin{tabular}{lc}
\hline \multicolumn{1}{c}{ Technique \& Device } & $\%$ \\
\hline ACD & 4.2 \\
\hline ACDF & 84.3 \\
\hline CDA & 7.3 \\
\hline Other & 4.2 \\
\hline Surgeons performing CDA occasionally & $47.8, \mathrm{n}=183$ \\
\hline Devices used & \\
\hline ProDisc-C & 33.3 \\
\hline Prestige (disc) LP & 10.9 \\
\hline Bryan Cervical Disc & 8.7 \\
\hline SECURE-C & 4.4 \\
\hline PCM disc prosthesis & 3.8 \\
\hline Mobi-C & 8.2 \\
\hline M6 & 8.7 \\
\hline Other & 21.9 \\
\hline
\end{tabular}

$\mathrm{LP}=$ Low Profile; $\mathrm{PCM}=$ Porous Coated Motion . tivities, whereas ACDF was rated the slowest (18.9\%). The ACDF procedure was expected to have the highest effectiveness on arm pain (87.5\%), followed by CDA (77.9\%), whereas ACD was rated the least effective (12.6\%). Postoperative neck pain was expected to be the highest after $\operatorname{ACD}(34.4 \%)$ and the lowest after CDA (37.8\%). However, CDA was also expected to give the highest complication risk $(28.0 \%)$. The ACD procedure was believed to have the highest risk for revision surgery (50.3\%), whereas ACDF was believed to have the lowest risk for revision surgery $(53.5 \%)$ (Table 4).

Figure 6 gives an overview of prognostic factors on clinical outcomes after surgery. Patients whose arm pain was greater than their neck pain were considered to have the best outcome $(91.6 \%)$. Other important factors were nonsmoking and age $<70$ years. A postoperative collar was expected to have the least effect on outcome (45.3\%).

\section{Discussion}

This survey among 383 international spine surgeons shows that CDA is not widely accepted as the standard treatment of $\mathrm{CDH}$, and that ACDF is still the procedure of choice among the majority of the responding surgeons when conservative treatment like pain medication and exercise therapy fails for more than 4-8 weeks. Low evidence for benefits and higher costs were the most important reasons for not offering CDA. The reported advantages of CDA included lower risk of ALD and preservation of motion of the neck. Among the CDA devices used, ProDisc-C was by far the one most applied.

Because cervical radiculopathy is self-limiting, most patients do not require surgery. There is limited evidence on the nonoperative management of cervical radiculopathy. According to our survey, pain medication is expected to have the highest effectiveness, followed by exercise therapy. Although the use of pain medication such as nonsteroidal antiinflammatory drugs for treating cervical radiculopathy has not been studied extensively yet, the effec- 

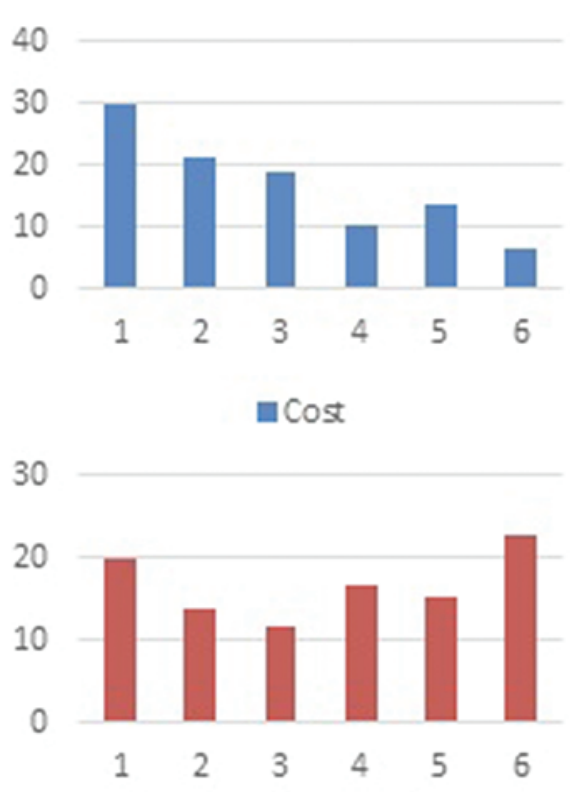

Insur ance will not cover it

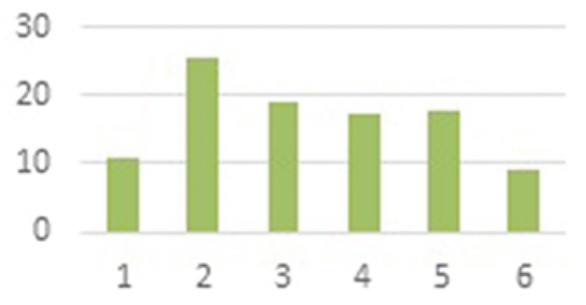

- Complications associated with arthroplasty

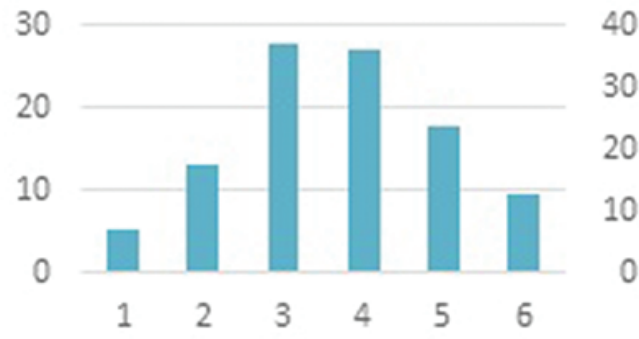

- Low concern for pseudarthr osis

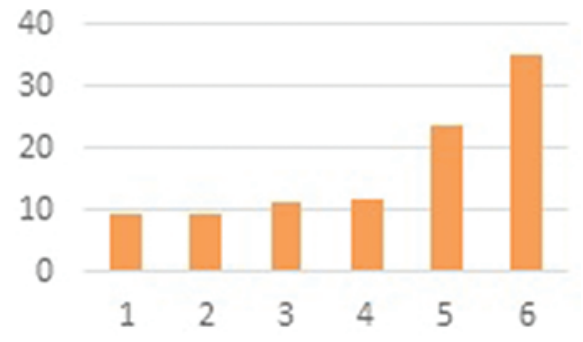

- Legal concerns

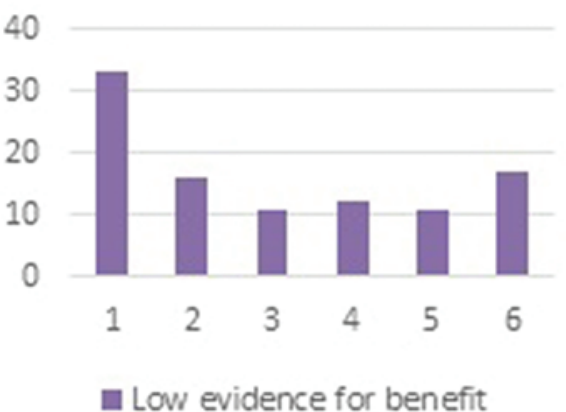

FIG. 4. Graphs showing reasons for not offering CDA (numbers on the y-axes represent percents), ranking from 1 as the most important to 6 as the least important (x-axes).

tive use of pain medication for lumbar radiculopathy suggest that it might also be beneficial for cervical radiculopathy. ${ }^{7}$ Exercise therapy such as manual therapy may provide short-term benefit for neck pain and radicular symptoms, but can also cause spinal cord injury, myelopathy, or even worsening of the symptoms. ${ }^{16,27}$ In combination with the lack of high-quality evidence on the effectiveness of manual therapy, it is not recommended as treatment for cervical radiculopathy.

The CDA was adopted as the standard procedure by only $7.3 \%$ of the surgeons. Reasons for not offering CDA were costs and lack of evidence on its benefits. In 2016, de Rooij et al. published a survey among Dutch neurosurgeons. ${ }^{5}$ They observed that despite the lack of solid evidence, $\mathrm{ACDF}$ is still the preferred technique to treat $\mathrm{CDH}$. In this Dutch survey, $47.9 \%$ of the surgeons considered a minimum of 8-12 weeks of radiculopathy as the optimal timing to perform surgery, whereas in the present international survey $44.5 \%$ of the surgeons considered 4-8 weeks as the optimal timing to perform CDH surgery. Differences may be explained by national and international guidelines and recommendations. To the best of our knowledge no high-quality studies are available considering timing of operation. In the Dutch guideline, 2 months of conservative treatment is recommended, ${ }^{21}$ whereas Carette and Fehlings suggest conservative treatment for 6-12 weeks. ${ }^{3}$

Advantages of CDA were lower risk of ALD and preservation of motion of the neck. However, only $7.3 \%$ of the surgeons adopted CDA as standard treatment for $\mathrm{CDH}$, mainly due to higher costs and low evidence for benefits. Recent studies have shown significant superior postoperative outcomes in neck functionality, neck pain score, arm pain score, and quality of life for CDA compared with $\mathrm{ACDF} \cdot{ }^{29,37}$

A recent meta-analysis of trials comparing CDA with ACDF showed that the risk of ALD was lower in patients treated with CDA. Moreover, it showed that CDA was associated with fewer adverse events, fewer reoperations, and better neurological success. These findings suggest that CDA is a good alternative for ACDF. However, due to different follow-up times, nonblinded study design, and poor heterogeneity of the results, this meta-analysis should be interpreted with caution. ${ }^{37}$

Zhong et al. showed in a recent study that CDA is also correlated with a lower risk for reoperation compared with ACDF, making it a safe and effective alternative for treat-

TABLE 3. Disadvantages of the 3 techniques (\%)

\begin{tabular}{|c|c|c|c|c|c|c|c|c|c|}
\hline \multirow[b]{2}{*}{ Disadvantage } & \multicolumn{3}{|c|}{ ACD } & \multicolumn{3}{|c|}{ ACDF } & \multicolumn{3}{|c|}{ CDA } \\
\hline & Small & Neutral & Big & Small & Neutral & Big & Small & Neutral & Big \\
\hline Risk of ALD & 21.4 & 42.6 & 36.0 & 15.9 & 36.9 & 47.2 & 54.4 & 33.7 & 11.9 \\
\hline Risk of dysphagia & 44.0 & 43.7 & 12.3 & 35.5 & 44.3 & 20.1 & 39.2 & 43.1 & 17.7 \\
\hline Risk of spondylolisthesis & 33.5 & 33.5 & 33.0 & 77.3 & 19.6 & 3.2 & 49.2 & 36.7 & 14.1 \\
\hline Costs & 69.1 & 28.3 & 2.6 & 24.3 & 54.9 & 20.8 & 4.1 & 14.5 & 81.4 \\
\hline Risk of revision surgery & 23.4 & 30.2 & 46.4 & 51.9 & 38.0 & 10.1 & 28.5 & 34.6 & 36.8 \\
\hline
\end{tabular}



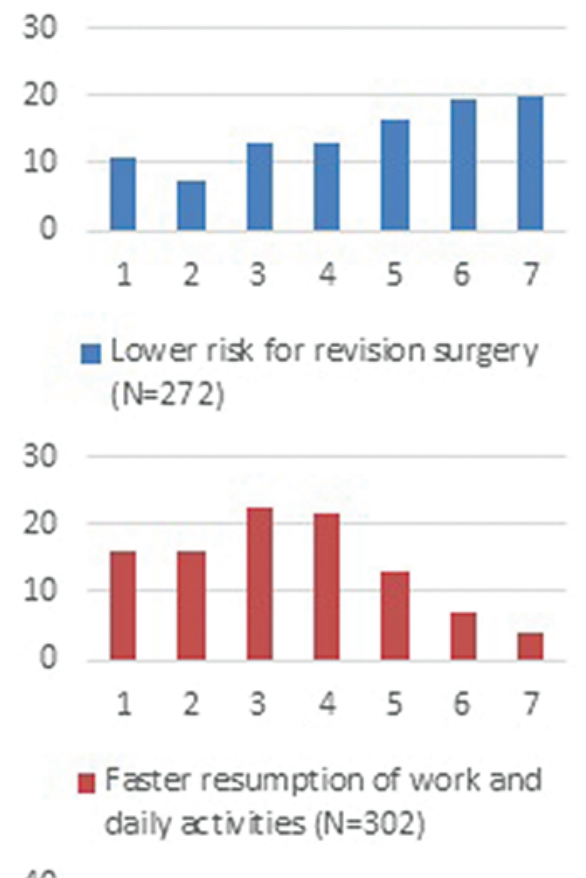

40

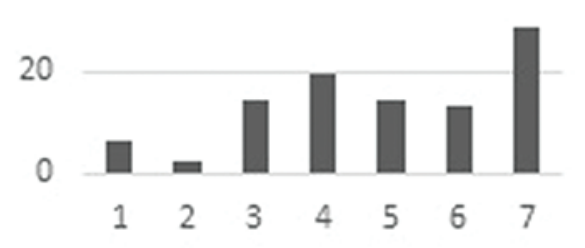

- Less complications of dysphagia

$(\mathrm{N}=331)$

FIG. 5. Graphs showing advantages of CDA over ACDF (numbers on the y-axes represent percents), ranking from 1 as the biggest advantage to 7 as the smallest (x-axes).

ing $\mathrm{CDH}^{42}$ Yu et al. also found that CDA had a significantly lower overall reoperation rate than $\mathrm{ACDF}^{40}$ Reasons for revision surgery are plate subsidence, plate lift-off causing dysphagia, and additional fusion at adjacent levels. In most cases, ALD and pseudarthrosis were the main reasons for reoperation..$^{19}$ A CDA was expected to solve the ALD problem by preserving movement in the affected levels after discectomy. ${ }^{2,6}$

Dysphagia is a common complication after anterior cervical spine surgery, and can occur in up to $71 \%$ of ACDF cases. ${ }^{28}$ However, the majority of the cases are transient and symptoms will disappear 12 weeks after surgery. Most respondents were neutral on whether ACD, ACDF, or CDA would have a higher risk for dysphagia. A pooled analysis consisting of 1512 patients who underwent CDA and 1199 patients who underwent ACDF showed that the incidence of dysphagia after CDA was significantly lower than after ACDF (9.46\% vs $12.09 \%$, respectively) ${ }^{41}$ Whether a difference in incidence of $2.63 \%$ for a usually self-limiting complication such as dysphagia is clinically relevant remains subject to debate.

Among the CDA devices used, ProDisc-C was by far the most frequently chosen. In an RCT study of 209 patients who were randomized into a ProDisc-C group and an
ACDF group, greater success after 6 months of follow-up was seen in the ProDisc-C group when comparing neurological success. ${ }^{19}$ Neurological success was defined as the maintenance of or improvement in results of neurological evaluations, including sensory, motor, and reflex functions. At 24 months of follow-up the difference in neurological success was not significant anymore. Also, the ProDisc-C group showed a significant improvement of the Neck Disability Index during follow-up. This is in accordance with the study of Yu et al., in which patients treated with CDA showed a significantly greater improvement in neck functionality, neck pain, and arm pain. ${ }^{40}$

According to the surgeons in this survey, a collar was expected to have the lowest effectiveness, whereas exercise therapy was expected to give the highest effectiveness after pain medication. In 2009, Kuijper et al. conducted an RCT in which 205 patients with recent-onset cervical radiculopathy were randomized between treatment with a semihard collar and taking rest for 3-6 weeks, twiceweekly sessions of physiotherapy for 6 weeks, or a waitand-see policy without a specific treatment. ${ }^{12}$ They showed that after 6 weeks of treatment with physical therapy or a collar, patients had a significantly faster reduction of neck and arm pain than those in the control group. An 
TABLE 4. Expectations of the 3 procedures (\%)

\begin{tabular}{lrrr}
\hline \multicolumn{1}{c}{ Outcome } & ACD & ACDF & CDA \\
\hline Return to work/daily activities & & & \\
\hline Fastest & 54.8 & 35.8 & 74.6 \\
\hline Neutral & 34.6 & 45.4 & 23.5 \\
\hline Slowest & 10.6 & 18.9 & 1.9 \\
\hline Effectiveness on arm pain & & & \\
\hline Most & 57.5 & 87.5 & 77.9 \\
\hline Neutral & 29.9 & 8.6 & 17.0 \\
\hline Least & 12.6 & 3.9 & 5.0 \\
\hline Postop neck pain & & & \\
\hline Most & 34.4 & 30.3 & 27.8 \\
\hline Neutral & 39.8 & 36.7 & 34.4 \\
\hline Least & 25.8 & 33.1 & 37.8 \\
\hline Complication risk & & & \\
\hline Highest & 23.2 & 11.1 & 28.0 \\
\hline Neutral & 36.2 & 38.0 & 38.9 \\
\hline Least & 40.6 & 50.9 & 33.1 \\
\hline Risk of revision surgery & & & \\
\hline Highest & 50.3 & 11.4 & 30.8 \\
\hline Neutral & 29.7 & 35.1 & 31.7 \\
\hline Least & 20.0 & 53.5 & 37.5 \\
\hline$\quad$ & &
\end{tabular}

explanation for this difference between the evidence and the expectations of the surgeons for prescribing a collar preoperatively could be the difference in the population of the study and the population that the surgeons see in practice. The patients included in the trial of Kuijper et al. were only included when the radiculopathy was present for less than 1 month, whereas patients usually get referred to surgeons after a period of conservative treatment. However, paradoxically $19.7 \%$ of the surgeons in this survey claimed that the optimal time to perform surgery for $\mathrm{CDH}$ is after less than 4 weeks of radiculopathy, suggesting that a portion of these procedures could have been prevented with conservative treatment.

Cost is considered to be one of the most important reasons for not offering CDA according to our survey. In 2013 a study was conducted on the cost-effectiveness of CDA versus $\mathrm{ACDF}^{22}$ In this study, the incremental cost-effectiveness ratio was used to summarize the cost-effectiveness, which is defined by the difference in cost between CDA and ACDF, divided by the difference in effectiveness. In this study the incremental cost-effectiveness ratio was \$2394 per quality-adjusted life year. This is lower than the commonly accepted threshold of $\$ 50,000$ per qualityadjusted life year, making CDA cost-effective. However, another study concluded that in order for CDA to be more cost-effective than ACDF, the device must function for at least 14 years. ${ }^{22}$ Furthermore, a retrospective matched cohort analysis of a national claims database consisting of 6635 patients who underwent ACDF and 327 patients who received $\mathrm{CDA}$ concluded that $\mathrm{CDA}$ resulted in lower total costs than ACDF at the time the first procedure was performed and after 24 months of follow-up. ${ }^{23}$ In this study the monthly cost of care was analyzed as well, and even so CDA was more effective in reducing the costs compared with ACDF.

The role of different conservative treatment modalities and the optimal timing of surgery for $\mathrm{CDH}$ are areas for further research. Failure of conservative treatment and the severity of pain and disability were seen as the most important indications for surgery. Further studies should also assess whether these subgroups of patients would benefit more from surgery than others. Our findings show that the cost of CDA plays a big role in whether to offer it. To our knowledge, no high-quality research on the implementation of CDA in surgical practice or the cost-effectiveness from society's perspective have been conducted. These studies should establish whether CDA, during and after a surgeon's learning curve, is superior to ACDF in terms of clinical outcomes, complication and reoperation rates, and cost-effectiveness in both the short and long term.

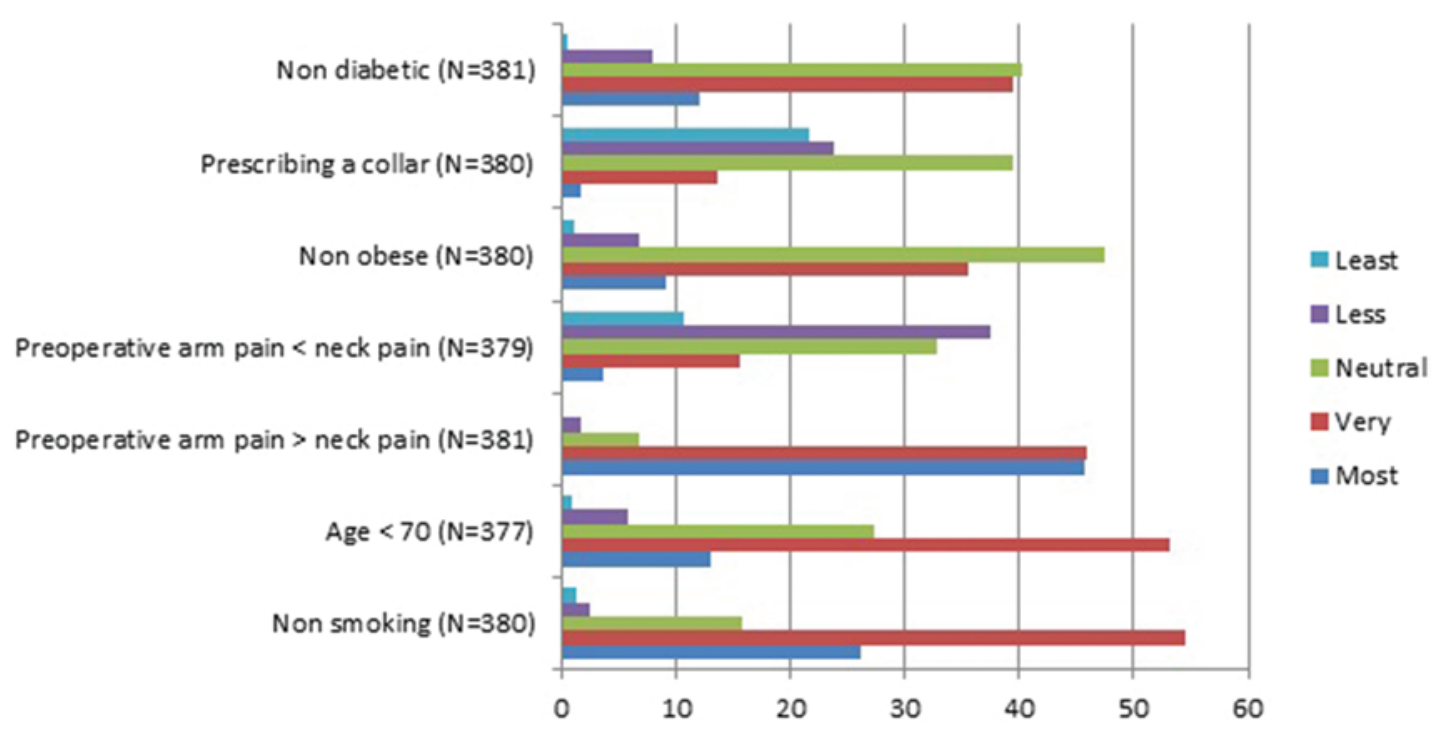

FIG. 6. Graph showing prognostic factors improving results after $\mathrm{CDH}$ surgery (numbers on the $\mathrm{x}$-axis represent percents). 
This study also has some limitations that have to be discussed. Surgeons performing CDA may be more prone to react positively due to their own belief and self-convincing experiences. However, the percentage of surgeons performing CDA as a first treatment option for symptomatic $\mathrm{CDH}$ was low. Furthermore, recommendations and clinical guidelines may differ between professional societies on the international and national level, and thus our results may only be applicable to the respondents in this survey. Finally, we limited the responders by only asking closed questions. Strengths include an international group of respondents representing all continents, with clinical experience ranging from 0 to 50 years. The response rate of $6.3 \%$ is another limitation. However, the response rate of this study is comparable to other surveys conducted among AOSpine members. ${ }^{20,33}$ Furthermore, only surgeons performing cervical disc surgery were eligible, so not all 6179 members could participate in this survey. Thus the response rate in fact should be higher than was calculated.

\section{Conclusions}

In this survey, CDA is not considered to be the standard treatment for $\mathrm{CDH}$, even though CDA was expected to reduce the risk of ALD and give the fastest recovery. The cost of CDA plays a big role in whether to offer it. More research on the implementation impact of CDA and the cost-effectiveness from society's perspective should be conducted.

\section{Acknowledgments}

Our gratitude goes out to AOSpine International for their financial support. Furthermore, the authors would like to acknowledge the help of mapchart.net in creating Fig. 1.

\section{References}

1. Alvin MD, Mroz TE: The Mobi-C cervical disc for one-level and two-level cervical disc replacement: a review of the literature. Med Devices (Auckl) 7:397-403, 2014

2. Basho R, Hood KA: Cervical total disc arthroplasty. Global Spine J 2:105-108, 2012

3. Carette S, Fehlings MG: Clinical practice. Cervical radiculopathy. N Engl J Med 353:392-399, 2005

4. Daffner SD, Hilibrand AS, Hanscom BS, Brislin BT, Vaccaro AR, Albert TJ: Impact of neck and arm pain on overall health status. Spine (Phila Pa 1976) 28:2030-2035, 2003

5. de Rooij JD, Gadjradj PS, Huygen FJ, Luijsterburg PA, Harhangi BS: Management of symptomatic cervical disk herniation: a survey among Dutch neurosurgeons. Spine (Phila Pa 1976) [epub ahead of print], 2016

6. DiAngelo DJ, Roberston JT, Metcalf NH, McVay BJ, Davis RC: Biomechanical testing of an artificial cervical joint and an anterior cervical plate. J Spinal Disord Tech 16:314-323, 2003

7. Eubanks JD: Cervical radiculopathy: nonoperative management of neck pain and radicular symptoms. Am Fam Physician 81:33-40, 2010

8. Fernström U: Arthroplasty with intercorporal endoprothesis in herniated disc and in painful disc. Acta Chir Scand Suppl 357:154-159, 1966

9. Goffin J, van Loon J, Van Calenbergh F, Plets C: Long-term results after anterior cervical fusion and osteosynthetic stabilization for fractures and/or dislocations of the cervical spine. J Spinal Disord 8:500-508, 499, 1995

10. Hilibrand AS, Robbins M: Adjacent segment degeneration and adjacent segment disease: the consequences of spinal fusion? Spine J 4 (6 Suppl):190S-194S, 2004

11. Hu Y, Lv G, Ren S, Johansen D: Mid- to long-term outcomes of cervical disc arthroplasty versus anterior cervical discectomy and fusion for treatment of symptomatic cervical disc disease: a systematic review and meta-analysis of eight prospective randomized controlled trials. PLoS One 11:e0149312, 2016

12. Kuijper B, Tans JT, Beelen A, Nollet F, de Visser M: Cervical collar or physiotherapy versus wait and see policy for recent onset cervical radiculopathy: randomised trial. BMJ 339:b3883, 2009

13. Le H, Thongtrangan I, Kim DH: Historical review of cervical arthroplasty. Neurosurg Focus 17(3):E1, 2004

14. Lee CK: Accelerated degeneration of the segment adjacent to a lumbar fusion. Spine (Phila Pa 1976) 13:375-377, 1988

15. Luo J, Gong M, Huang S, Yu T, Zou X: Incidence of adjacent segment degeneration in cervical disc arthroplasty versus anterior cervical decompression and fusion meta-analysis of prospective studies. Arch Orthop Trauma Surg 135:155160,2015

16. Malone DG, Baldwin NG, Tomecek FJ, Boxell CM, Gaede SE, Covington CG, et al: Complications of cervical spine manipulation therapy: 5-year retrospective study in a singlegroup practice. Neurosurg Focus 13(6):ecp1, 2002

17. Muheremu A, Niu X, Wu Z, Muhanmode Y, Tian W: Comparison of the short- and long-term treatment effect of cervical disk replacement and anterior cervical disk fusion: a meta-analysis. Eur J Orthop Surg Traumatol 25 (Suppl 1):S87-S100, 2015

18. Mummaneni PV, Haid RW: The future in the care of the cervical spine: interbody fusion and arthroplasty. Invited submission from the Joint Section Meeting on Disorders of the Spine and Peripheral Nerves, March 2004. J Neurosurg Spine 1:155-159, 2004

19. Murrey D, Janssen M, Delamarter R, Goldstein J, Zigler J, Tay B, et al: Results of the prospective, randomized, controlled multicenter Food and Drug Administration investigational device exemption study of the ProDisc-C total disc replacement versus anterior discectomy and fusion for the treatment of 1-level symptomatic cervical disc disease. Spine J 9:275-286, 2009

20. Nater A, Tetreault LL, Davis AM, Sahgal AA, Kulkarni AV, Fehlings MG: Key preoperative clinical factors predicting outcome in surgically treated patients with metastatic epidural spinal cord compression: results from a survey of 438 AOSpine International members. World Neurosurg 93:436448, 448.e1-448.e415, 2016

21. Nederlands Vereniging voor Neurochirurgie: [Treatment of cervical radiculopathy caused by a cervical herniated nucleus pulposus.] Leiden: Nederlands Vereniging voor Neurochirurgie, 2010 (Dutch) (http://www.med-info.nl/Rich tlijnen/Neurologie/Cervicaal\%20radiculair\%20syndroom. pdf) [Accessed December 9, 2016]

22. Qureshi SA, McAnany S, Goz V, Koehler SM, Hecht AC: Cost-effectiveness analysis: comparing single-level cervical disc replacement and single-level anterior cervical discectomy and fusion: clinical article. J Neurosurg Spine 19:546554,2013

23. Radcliff K, Zigler J, Zigler J: Costs of cervical disc replacement versus anterior cervical discectomy and fusion for treatment of single-level cervical disc disease: an analysis of the Blue Health Intelligence database for acute and long-term costs and complications. Spine (Phila Pa 1976) 40:521-529, 2015

24. Radhakrishnan K, Litchy WJ, O'Fallon WM, Kurland LT: Epidemiology of cervical radiculopathy. A population-based study from Rochester, Minnesota, 1976 through 1990. Brain 117:325-335, 1994 
25. Rao MJ, Nie SP, Xiao BW, Zhang GH, Gan XR, Cao SS: Cervical disc arthroplasty versus anterior cervical discectomy and fusion for treatment of symptomatic cervical disc disease: a meta-analysis of randomized controlled trials. Arch Orthop Trauma Surg 135:19-28, 2015

26. Ren C, Song Y, Xue Y, Yang X: Mid- to long-term outcomes after cervical disc arthroplasty compared with anterior discectomy and fusion: a systematic review and meta-analysis of randomized controlled trials. Eur Spine J 23:1115-1123, 2014

27. Rhee JM, Yoon T, Riew KD: Cervical radiculopathy. J Am Acad Orthop Surg 15:486-494, 2007

28. Rihn JA, Kane J, Albert TJ, Vaccaro AR, Hilibrand AS: What is the incidence and severity of dysphagia after anterior cervical surgery? Clin Orthop Relat Res 469:658-665, 2011

29. Sasso RC, Anderson PA, Riew KD, Heller JG: Results of cervical arthroplasty compared with anterior discectomy and fusion: four-year clinical outcomes in a prospective, randomized controlled trial. Orthopedics 34:889, 2011

30. Schoenfeld AJ, George AA, Bader JO, Caram PM Jr: Incidence and epidemiology of cervical radiculopathy in the United States military: 2000 to 2009. J Spinal Disord Tech 25:17-22, 2012

31. Schwab JS, Diangelo DJ, Foley KT: Motion compensation associated with single-level cervical fusion: where does the lost motion go? Spine (Phila Pa 1976) 31:2439-2448, 2006

32. Smith GW, Robinson RA: The treatment of certain cervicalspine disorders by anterior removal of the intervertebral disc and interbody fusion. J Bone Joint Surg Am 40-A:607-624, 1958

33. Tetreault LA, Nouri A, Singh A, Fawcett M, Fehlings MG: Predictors of outcome in patients with cervical spondylotic myelopathy undergoing surgical treatment: a survey of members from AOSpine International. World Neurosurg 81:623-633, 2014

34. Verma K, Gandhi SD, Maltenfort M, Albert TJ, Hilibrand AS, Vaccaro AR, et al: Rate of adjacent segment disease in cervical disc arthroplasty versus single-level fusion: metaanalysis of prospective studies. Spine (Phila Pa 1976) 38:2253-2257, 2013

35. Wigfield C, Gill S, Nelson R, Langdon I, Metcalf N, Robertson J: Influence of an artificial cervical joint compared with fusion on adjacent-level motion in the treatment of degenerative cervical disc disease. J Neurosurg 96 (1 Suppl):17-21, 2002

36. Wu JC, Liu L, Wen-Cheng H, Chen YC, Ko CC, Wu CL, et al: The incidence of adjacent segment disease requiring surgery after anterior cervical diskectomy and fusion: estimation using an 11-year comprehensive nationwide database in Taiwan. Neurosurgery 70:594-601, 2012
37. Xie L, Liu M, Ding F, Li P, Ma D: Cervical disc arthroplasty (CDA) versus anterior cervical discectomy and fusion (ACDF) in symptomatic cervical degenerative disc diseases (CDDDs): an updated meta-analysis of prospective randomized controlled trials (RCTs). Springerplus 5:1188, 2016

38. Yi S, Kim SH, Shin HC, Kim KN, Yoon DH: Cervical arthroplasty in a patient with Klippel-Feil syndrome. Acta Neurochir (Wien) 149:805-809, 2007

39. Yoss RE, Corbin KB, MacCarty CS, Love JG: Significance of symptoms and signs in localization of involved root in cervical disk protrusion. Neurology 7:673-683, 1957

40. Yu L, Song Y, Yang X, Lv C: Systematic review and metaanalysis of randomized controlled trials: comparison of total disk replacement with anterior cervical decompression and fusion. Orthopedics 34:e651-e658, 2011

41. Zhong ZM, Li M, Han ZM, Zeng JH, Zhu SY, Wu Q, et al: Does cervical disc arthroplasty have lower incidence of dysphagia than anterior cervical discectomy and fusion? A metaanalysis. Clin Neurol Neurosurg 146:45-51, 2016

42. Zhong ZM, Zhu SY, Zhuang JS, Wu Q, Chen JT: Reoperation after cervical disc arthroplasty versus anterior cervical discectomy and fusion: a meta-analysis. Clin Orthop Relat Res 474:1307-1316, 2016

\section{Disclosures}

The authors report no conflict of interest concerning the materials or methods used in this study or the findings specified in this paper.

\section{Author Contributions}

Conception and design: Harhangi, Gadjradj. Acquisition of data: all authors. Analysis and interpretation of data: Harhangi, Gadjradj. Drafting the article: Chin-See-Chong, Gadjradj. Critically revising the article: Harhangi, Gadjradj, Boelen. Reviewed submitted version of manuscript: all authors. Statistical analysis: Gadjradj. Administrative/technical/material support: all authors. Study supervision: Harhangi, Gadjradj, Boelen.

\section{Supplemental Information \\ Online-Only Content}

Supplemental material is available online.

Questionnaire. https://thejns.org/doi/suppl/10.3171/2016.11. FOCUS16338.

\section{Correspondence}

Biswadjiet Sanjay Harhangi, Erasmus Medical Center, Neurosurgery, 's-Gravendijkwal 230, Rotterdam, 3015 CE, Netherlands. email: b.s.harhangi@erasmusmc.nl. 